\title{
Applied PhD research in a work-based environment: an activity theory-based analysis
}

\author{
S.N. Granata ${ }^{1}$ \\ Students of Master of Educational Studies \\ University of KU Leuven \\ Leuven, Belgium \\ E-mail: stefano.granata@student.kuleuven.be \\ F. Dochy \\ Full Professor at Faculty of Psichology and Educational Studies \\ University of KU Leuven \\ Leuven, Belgium \\ E-mail: filip.dochy@ppw.kuleuven.be
}

Conference Key Areas: Industry and engineering education, Integration of research in engineering education, University - business: cooperation and inspiration.

Keywords: Activity theory, industry and engineering education, PhD.

\section{INTRODUCTION}

A clear and concise definition of the $\mathrm{PhD}$ degree valid at the international level is difficult to attain because educational systems differ from country to country. However, several authors [1],[2],[3] agree on the core component of doctoral education, defined by the European University Association as "original research performed within academic standards following an examination by a committee of experts"[1].

Under this tenet, a PhD degree can be included in the paradigm of "expansive learning", where the PhD students learn something that "is not yet there" [4]. The students become part of a community, accompanied by its rules, conventions and instruments. These features of the PhD degree allow for an interpretation of the PhD program through the lens of activity theory [5]. Thus, the PhD can be interpreted as an activity system, where the PhD students and the PhD research are the subject and the object of the primary activity system, respectively. However, the other elements of the activity system are not uniquely defined. This is due to the fact that the PhD implies a large network of activity systems and the nature of elements depends on the stakeholders involved in the network. The relationship between stakeholders has evolved over time: in the past, the PhD degrees were based on the master-apprentice model, where student learning was built on the supervisor/student

\footnotetext{
${ }^{1}$ Stefano Nicola Granata

S.N. Granata

Stefano.granata@student.kuleuven.be
} 
interaction. In recent years, this approach is being gradually replaced by a more modern combined-integrated model [3], where more stakeholders contribute to the learning. Industry and universities have become inextricably connected and government institutions often mediate their interactions, which further expands the connection. In this scenario, an increasing trend toward collaborative PhD degrees in which universities and industry partners cooperate closely is observed [6].

\section{GOAL OF THE RESEARCH}

The purpose of the research is to define the elements of the PhD activity systems and to discover the innovative practices generated by the involvement of industry in the network of activity systems. To do so, a literature review is conducted to define the framework of operation and a case study is presented to validate the applicability of the activity theory to $\mathrm{PhD}$ programs. In the following, two activity systems are defined: (a) an "academic" PhD degree performed at university, with little or no intervention of industry and (b) a "semi-industrial" $\mathrm{PhD}$ degree performed in a research centre in close collaboration with industry.

\section{METHODOLOGY}

\subsection{Literature review}

The strategy focused on the research of scientific articles about PhD programs in a work-based environment. Relevant articles were selected on the basis of content based and method based criteria. Content-based criteria were: (a) the study focused on the Philosophical Doctorate; (b) the study related to PhD degrees in the fields of Physical, Life, and Applied Science; (c) the study described one or more of the 7 elements of the principal activity system; and (d) the study elucidated the effects subsequent to industry or knowledge-based society intervention on PhD research. Method-based criteria were: (a) the study contained empirical data restricted on one or more of the 7 elements of the principal activity system; (b) the study contained specific methodology and finding sections; (c) the study reported queries conducted since 2000, date when the knowledge-based society first appears among the strategic objectives of the European Union [1]; and (d) the study was geographically delimited to the modern definition of the Western World. Narrative review was used to analyse the selected articles.

\subsection{Case study}

A qualitative study using semi-structured interviews was performed to acquire rich and complex information on the academic and semi-industrial PhDs. The study was performed within the faculty of Electrical Engineering of the KU Leuven (ESAT) and the Inter-Universitary Center for Microelectronics (IMEC). ESAT is the branch of KU Leuven that offers study programs in electrical engineering, electronics, and information processing and has laboratory-like facilities. The research department includes more than $300 \mathrm{PhD}$ students. In contrast, IMEC is a research centre whose mission is to deliver industrially relevant technological solutions. It acts as a bridge between academic research and its associated industrial applications. As such, it offers joint PhD programs under KU Leuven in collaboration with private industry partners. Most of the facilities in IMEC are similar to those used in industrial production lines, which differs significantly from the working environment at ESAT. With these features, IMEC is an ideal example of semi-industrial environment settings for the development of a PhD. A theory-based sample was chosen for the research [7]. Fourteen PhD students belonging to ESAT were interviewed. PhD 
students were in the third year of four-year PhD research program with PhD students that graduated after August 2012 also being included in the analysis. Six of the students interviewed performed their $\mathrm{PhD}$ research in an academic environment, with their offices and facilities situated at the University, while another eight performed their $\mathrm{PhD}$ research in a semi-industrial environment, with their offices and facilities situated at IMEC. Interviews were conducted during the months of February and March 2013. PhD students were contacted in person, by email or telephone and were partially linked to the professional network of the author. Out of 62 contacted persons contacted, 14 voluntarily agreed to participate in the study. The questions for the interviews were formulated on the basis of the differences between the academic and semi-industrial PhD highlighted from the literature review. Anonymity was guaranteed. Interviews were transcribed verbatim using a text editor.and were subsequently analysed following a thematic approach [8]. Transcripts were then imported into Nvivo 10 software and coded. Codes followed the terminology indicated in the previous literature review and were retrieved iteratively until a coherent coding system was achieved. In this way, it was possible to detect recurrent patterns across the interviews, which were successively organised in themes and sub-themes.

\section{FINDINGS}

\subsection{Literature review}

The elements of the PhD activity system were identified and the differences between academic and semi-industrial PhDs were concerning four elements: (a) subject, i.e. the PhD student; (b) object, i.e. the PhD topic; (c) outcome, i.e. the PhD research; and (d) division of labour, i.e. the supervision. Minor differences in other elements of the activity system were also present.

According to [1] the integration of $\mathrm{PhD}$ students into academic and industrial communities stimulated the development of a broad range of skills. This objective was portrayed in the metaphor of moulding "T-shape individuals" [1], referring to both, people who have gained mastery of a certain subject, and acquired a set of soft skills. The sets of skills developed by PhD graduates was categorized into three groups [1]: (a) Technical skills, such as technical proficiency, in-depth knowledge, critical judgment, etc.; (b) Transferable skills, such as environmental awareness, communication, creativity, independence, team-work, etc.; (c) Management skills, such as leadership, entrepreneurial mindset, Intellectual Property management, commercialisation, etc. According to the study of Manathunga [9], technical skills were present in both academic and semi-industrial PhDs. Conversely, the intervention of industry generated educational situations where transferable and management skills were strongly developed by semi-industrial PhDs. The employment outcomes of academic and semi-industrial PhDs reported by [9] showed a significantly higher percentage of semi-industrial PhD employed in the nonacademic sector.

In most of the academic PhDs, supervision consisted of a master/apprentice relationship [10], where the students were informed of the topic by their advisors. Students and advisors interacted in an almost exclusively dyadic relationship. Conversely, the programs of semi-industrial PhDs were often highly structured and advisors had the additional task of regulating the progress of the research according to an established plan [2] along with the scientific guidance of the students. For this reason, a progressive shift toward a collaborative supervision style was suggested in [10]. The supervision was evidently more complex in semi-industrial PhDs with the group of supervision being represented by, at the very least, one academic advisor (e.g. a professor) and one industrial supervisor (e.g. an R\&D professional). In 
addition to these, other individuals could also join the supervision staff including members of academia, career development experts, project managers or government representatives [1].

In semi-industrial $\mathrm{PhDs}$ the approach shifted from curiosity-driven research to application-driven research_[11] and with it, the $\mathrm{PhD}$ outcome. This was a result of the alignment of university and industry strategies and the selection of a topic fitting for both parts. The selected topic often fell in the field of applied research, midway between long-term basic research and short-term experimental development. [12].

As such, academic and semi-industrial PhDs can be defined as primary activity systems. A proposition for the different elements for academic and semi-industrial PhDs can be described as follow: (a) subject, a T-shape individual in semi-industrial $\mathrm{PhDs}$ is empowered with technical, transferable and management skills and replaces the academic-to-be of the academic $\mathrm{PhD}$, whose strength is with in-depth technical knowledge; (b) object, a curiosity-driven topic in the academic $\mathrm{PhD}$ is replaced by an application-driven topic in the semi-industrial $\mathrm{PhD}$, in line with the industrial roadmap; (c) community, a joint network of university, industry, and institutions in semiindustrial PhD substitutes university in the academic PhD; (d) division of labour, a dyadic supervision model in the academic $\mathrm{PhD}$ is transformed into a collaborative model in the semi-industrial PhD; (e) rules, in the academic PhD guidelines strongly depend on the way dyadic supervision is structured and are non-standardised while in a semi-industrial $\mathrm{PhD}$, the rules are strict and predetermined; (f) outcome, the general knowledge created in the academic $\mathrm{PhD}$, whether focused on theory or application is now restricted to a tangible product in the semi-industrial PhD; and (g) instruments, laboratory facilities of the academic PhD are supported by industry facilities of the semi-industrial PhD, such as large-scale machines, additional funding and business departments.

\subsection{Case study}

Most of the participants stated that they were stronger in both technical, transferable and management skills having participated in a PhD program, irrespective of academic or semi-industrial. These three kinds of competences were coded in the interviews for a total of 259 times. However, the balance between these skills was perceived as much dependent on the type of PhD. Specifically, academic PhDs felt an improvement on technical skills and communication within academia, while semiindustrial PhD highlighted the management competences and the vision they could acquire on their $\mathrm{PhD}$ project. Both academic and semi-industrial $\mathrm{PhD}$ found their technical background broadened and deepened.

All PhD students indicated their willingness to stay within the research sector after graduation. The job options they considered after graduation were either in academia or industry, and the choice was motivated by personal interest. As such, no significant differences on their professional futures were found between the academic and the semi-industrial PhDs.

The participants considered their research a work that "Cannot be done alone" (semiindustrial PhD student) but the terms related to collaboration were mentioned more often by semi-industrial PhDs than academic PhDs. On average, semi-industrial PhDs mentioned this collaboration 44 times during the interview, while academic PhDs only 28 times. A total of 133 and 407 words related to this subject were coded in academic and semi-industrial PhDs, respectively. Furthermore, the participants indicated a network of collaborations. The nature of these collaborations changed according to the type of $\mathrm{PhD}$. The network of collaborations described by academic PhDs was homogenous. The coded terms referred mostly to professional positions of 
PhDs students, postdoctoral researchers or similar (i.e. permanent researcher, professors). Semi-industrial PhDs in IMEC listed a more diverse network of collaboration. In addition to other academics, they also indicated close collaborations with industry. Academic collaboration was coded for a total of 168 times, while industrial collaboration was coded 270 times and included professionals such as technicians, operators, and process engineers. Some semi-industrial PhDs also stated that they worked side-by-side with tool providers or material suppliers for the joint development of certain products.

All participants received guidance during their $\mathrm{PhD}$, although there were differences between academic and semi-industrial PhDs. These differences were identified in the concepts of scientific and practical guidance. On one hand, academic PhDs stressed the scientific feature of their guidance. The interactions with their advisors were based on scientific questions and these discussions could involve experts in the field. On the other hand, semi-industrial PhDs commented on both a scientific and practical guidance. In addition to scientific questions, semi-industrial PhDs received support to individuate the best path to reach their goals. Academic PhDs referred 22 and 12 times to scientific and practical guidance, respectively, while semi-industrial PhDs referred 45 times to scientific and 40 times to practical guidance.

Academic PhDs usually had one central figure to whom they asked their questions. Most often this central figure was their promoter, but examples of this being their copromoter or postdoctoral researcher were also found. The questions students posed dealt with mainly scientific issues, and only rarely were practicalities discussed. As mentioned, semi-industrial PhDs often had at least two figures to guide them: a promoter to whom they addressed their scientific query and a daily supervisor who answered the more practical aspects of the research.

The participants commented on the interaction with their promoters/supervisors. Academic PhDs met their advisor irregularly. Anytime they needed their help, they were free to knock on their advisor's door and walk in for discussion. Semi-industrial PhDs described different interactions with their promoter and their daily supervisor. They met their promoter regularly around once a month. Moreover, the participants stated that it was very difficult to meet their promoter in between regular meetings, ad hoc. Two types of interactions with daily supervisors were described by semiindustrial PhDs. On one hand, five participants talked about daily interactions, very similar to that of academic PhDs with their central advisor. On the other hand, three participants witnessed weekly interactions with a fix schedule, and had few occasions to meet their daily supervisor outside planned meetings. Semi industrial PhDs that could meet their supervisor frequently and irregularly found this interaction very important for their PhD. They often considered themselves "lucky".

Academic and semi-industrial PhDs also interacted with fellow PhD students and postdoctoral researchers. These interactions were different from the collaborations described previously. Indeed, the participants defined the interactions with terms such as "favour" or "help", and the issues faced were not exclusively related to the PhD research. PhDs and their fellows could discuss their concerns or helped each other in the personal domain of expertise. Interestingly, semi-industrial PhDs talked about these interactions more extensively than academic PhDs and seemed to be more conscious of the potential of interactions. If they could not find answers from their advisors, they searched literature, but also turned to closer colleagues. If this could not help either they addressed their questions to other research groups. Furthermore, semi-industrial PhDs with weekly-based interactions turned more often to colleagues or other research groups. Therefore, PhDs student with weekly-based supervision valued much more interactions with other colleagues than PhD students with daily-based supervision. Many participants commented on how the fact that they 
turned to other people could eventually lead to fruitful collaborations. The network that they created could speed their experiments beyond formal operational boundaries, with strong benefits to the PhD research.

Most PhDs considered their research program aimed toward a practical application. Often the practical applications of the PhDs were also accompanied by theoretical advancements in the field of study. These theoretical findings strengthened the PhD research and increased the possibility to publish. No significant differences in the $\mathrm{PhD}$ outcomes were highlighted between academic and semi-industrial PhDs.

In light of the above, a common pattern for the semi-industrial $\mathrm{PhD}$ research can be drafted.The community where semi-industrial PhDs performed the research was more complex than in the academic PhD. The collaboration with people without an academic profile, i.e. industrials and process engineers is apparent in the semiindustrial environment. Clearly, this increased network complexity stimulated the learning of management competences more than in academic PhDs. Furthermore, to help them perform their research in this complex scenario, PhDs also received practical guidance. This guidance was deemed optimal if it was based on frequent and irregular interactions with their daily supervisor. If this was not the case, semiindustrial PhDs needed to turn to other figures to be able to perform their research effectively.

\section{LIMITATION AND FUTURE RESEARCH}

The main limitation of the literature review was the geographical heterogeneity of the articles reviewed that might affect the extrapolation of a single model for the academic and the semi-industrial PhDs at the international level. For future research, the PhD comparison should be modelled at a national level and refined according to the specifications of the particular education system.

The criteria for the sample selection represent the main limitation of the case study. First, all participants were affiliated to a single faculty of applied science, i.e. Electronic Engineering of KU Leuven. This means that the PhD topics belonged to the same scientific field and could be very similar between each other. This homogeneity could limit the validity of the findings to a very narrow context. i.e. Electronic Engineering at KU Leuven.

Second, most of the PhD students that were contacted were also part of the professional network of the author. Although the participation was voluntarily, this influenced the participation rate. Thus, the findings might be biased by the chosen sample. For future research, the query should be extended to all faculties of hard science of the different universities that collaborate with IMEC. In this way, the analysis would generate a more complete overview of the features of academic and semi-industrial PhD and the validity of the results could be more easily generalized.

\section{CONCLUSION}

The elements of the academic and semi-industrial PhD activity system can be withdrawn from the results of the literature review and the case study. A graphical representation of the activity systems is reported in Fig. 1.

There are both common and different elements between the academic and the semiindustrial PhD that are generated by the intervention of industry in the PhD research. The differences are highlighted in terms of the subject, community, division of labour, and instrumentation of the activity system. 


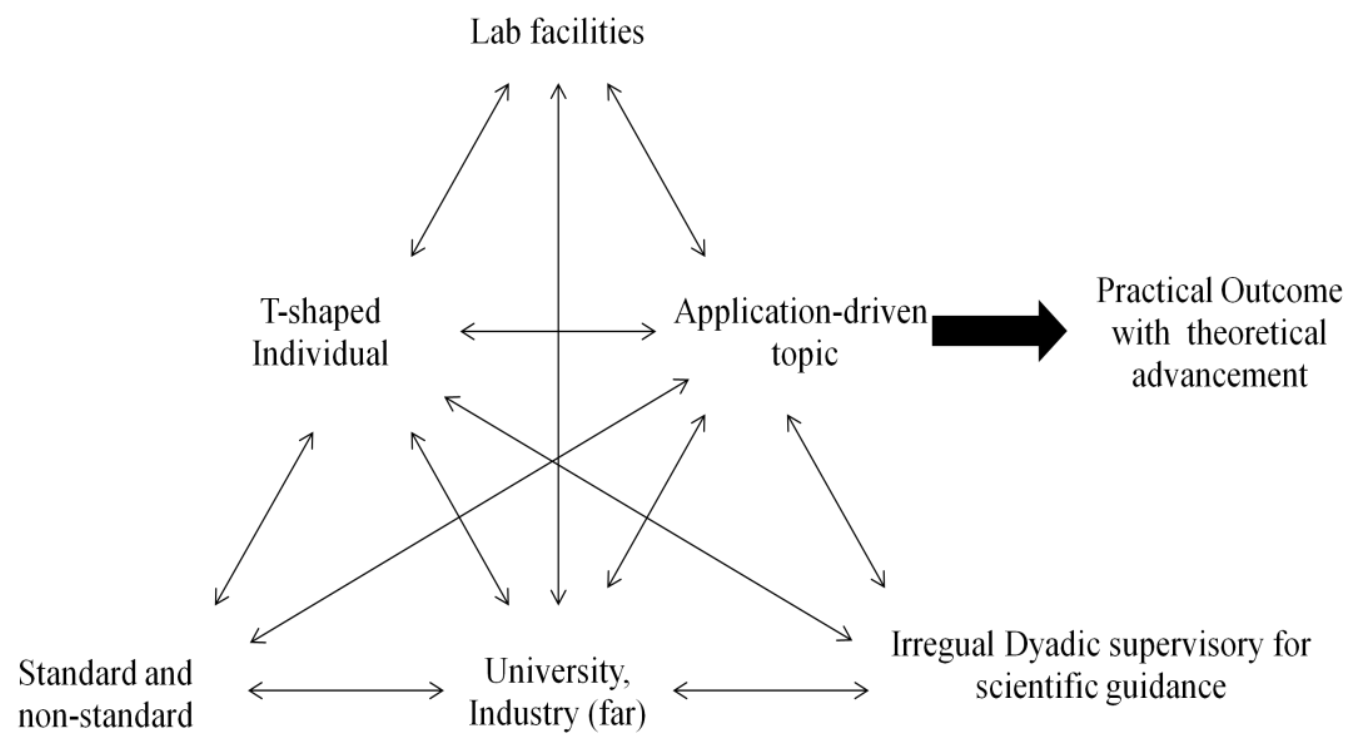

Lab and Industrial facilities

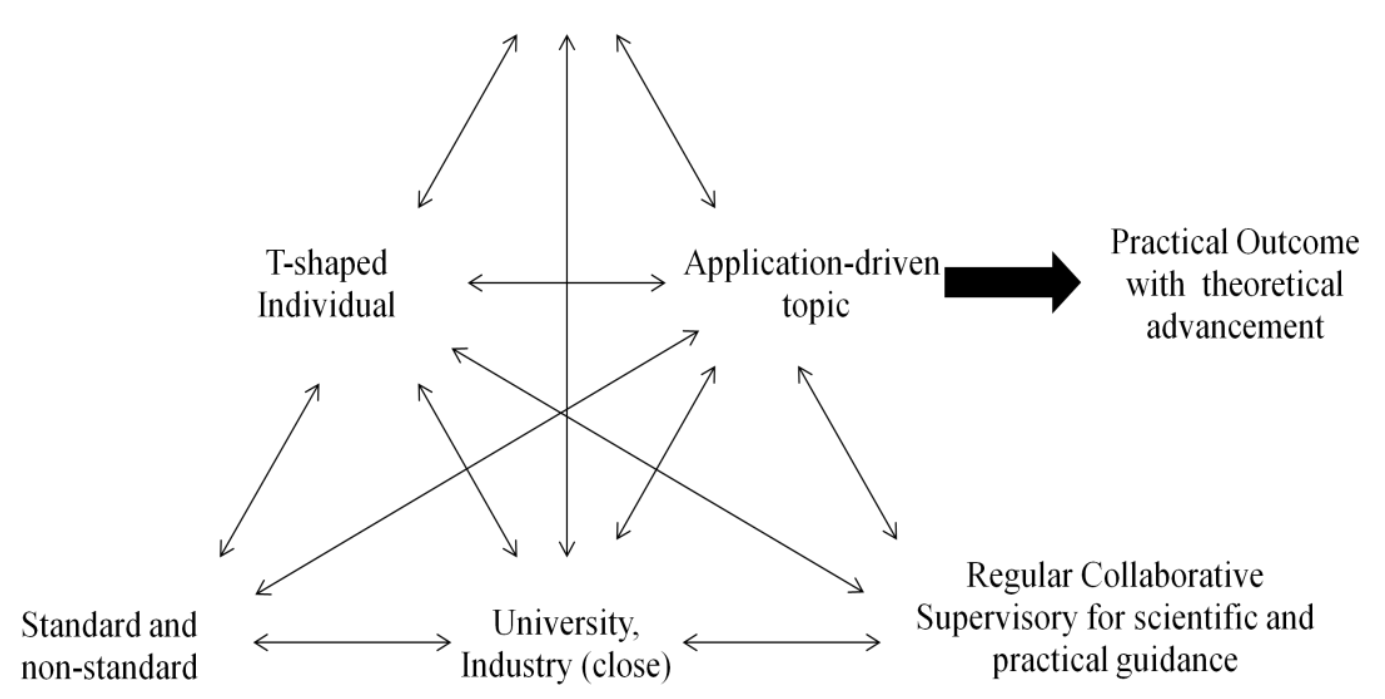

Figure 1 Principal activity system for an academic $\mathrm{PhD}$ (top) and semi-industrial $\mathrm{PhD}$

(bottom)

The semi-industrial PhD students face different types of educational situations. For their research they use industrial facilities and interact with a number of different people. In this way, they develop management skills and make use of interactions within their community. The supervision style of semi-industrial PhD is complex. If supported by frequent and irregular supervision, the complexity increases but strengthens the $\mathrm{PhD}$ research. If unsupported by frequent supervision, PhD students value the supervision less and create their own network of colleagues and industry professionals that enable them to effectively perform their research. However, the creation of the network might depend on the individual character of the PhD students: 
this feature may affects whether or not they can collaborate well with an informa supervision and might hinder the PhD research.

Therefore, irregular and frequent interaction between advisors and semi-industrial PhDs students need to be stressed and standardised. In this way, the creation of the network is less needed. The learning process of semi-industrial PhDs can be faster, with positive influence on the research outcome.

The common elements between academic and semi-industrial PhD are in the object, the rules and the outcome. Results of the case study are in contradiction with the literature review, which claimed differences in these elements. However, the differences between case study and literature review can be partially explained by the aforementioned limitations of the study.

\section{REFERENCES}

[1] L. Borrell-Damian, T. Brown, A. Dearing, J. Font, S. Hagen, J. Metcalfe, and J. Smith, "Collaborative Doctoral Education: University-Industry Partnerships for Enhancing Knowledge Exchange," Higher Education Policy, vol. 23, no. 4, pp. 493-514, Dec. 2010.

[2] P. Green and R. Usher, "Fast Supervision: Changing supervisory practice in changing times," Studies in Continuing Education, vol. 25, no. 1, pp. 37-50, May 2003.

[3] K. M. Harman, "Challenging Traditional Research Training Culture: Industry-oriented Doctoral Programs in Australian Cooperative Research Centres," in Cultural Perspectives on Higher Education, J. Välimaa and O.-H. Ylijoki, Eds. Dordrecht: Springer Netherlands, 2008, pp. 179-195.

[4] Y. Engestrom, "Studies of Expansive Learning: Foundations, Findings and Future Challenges," EDUC RES REV-NETH, vol. 5, no. 1, pp. 1-24, 2010.

[5] Y. Engeström, Learning by Expanding: An Activity-theoretical Approach to Developmental Research. Orienta-Konsultit Oy, 1987.

[6] A. Kolmos, L. B. Kofoed, and X. Y. Du, "PhD students' work conditions and study environment in university- and industry-based PhD programmes," European Journal of Engineering Education, vol. 33, no. 5, pp. 539-550, Oct. 2008.

[7] M. Patton, "Desing Qualitative Studies," in Qualitative Evaluation and Research Methods, Beverly Hills, CA: Sage, 1990, pp. 169-186.

[8] V. Braun and V. Clarke, "Using thematic analysis in psychology," Qualitative Research in Psychology, vol. 3, no. 2, pp. 77-101, Jan. 2006.

[9] Manathunga, C., Pitt, R., Cox, L., Boreham, P., Mellick, G., and Lant, P., "Evaluating industry-based doctoral research programs: perspectives and outcomes of Australian Cooperative Research Centre graduates," Studies in Higher Education, vol. 37, no. 7, pp. 843-858, Aug. 2011.

[10] Malfroy, J., (2011), "The impact of university-industry research on doctoral programs and practices," Studies in Higher Education, vol. 36, no. 5, pp. 571-584.

[11] Malfroy, J., (2005), "Doctoral supervision, workplace research and changing pedagogic practices," Higher Education Research \& Development, vol. 24, no. 2, pp. 165-178, 2005. 
$41^{\text {th }}$ SEFI Conference, $16-20$ September 2013, Leuven, Belgium

[12] OECD, "Frascati Manual 2002: Proposed Standard Practice for Surveys on Research and Experimental Development, The Measurement of Scientific and Technological Activities," OECD Publishing, 2002. 